\title{
Probability Estimation of Final Height
}

\author{
TOSHIAKI TANAKA, KAZUO KOMATSU*, GORO TAKADA**, \\ MASAHIRO MIYASHITA***, AND TADASHI OHNO\# \\ Department of Endocrinology \& Metabolism, National Children's Medical Research Center, Tokyo 154-8509, \\ *Yuri General Hospital, Honjo 015, **Akita University, Akita 010,

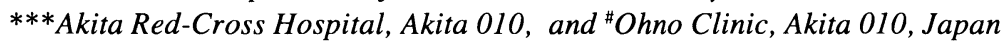

\begin{abstract}
. 13,707 longitudinal records of individuals (6,749 boys and 6,958 girls) from 6 years to 17 years were fitted by means of a smoothing cubic spline function and the factors influencing the change in height SDS during puberty were analysed. Children are divided into subgroups with 0.2 SD intervals according to height SDS at 6 years. Shorter children in subgroups at 6 years tend to increase their final height SDS by entering puberty later and making their height at onset of pubertal growth spurt (PGS) relatively taller. On the other hand taller children in subgroups at 6 years tend to decrease their final height SDS by entering puberty early and make height at PGS relatively shorter. The percentage distribution of a final height SDS against subgroups at 6 years also shows this tendency. This figure is useful in predicting the probability of final height SDS in the clinical field of growth disorders.
\end{abstract}

Key words: Short children, Tall children, Final height, Puberty

(Endocrine Journal 45: S145-S149, 1998)

NATURAL growth of short children is not fully understood. It is necessary for pediatric endocrinologists to predict final height in the clinical field of growth disorders in order to decide who should be treated. Although several methods to predict final height have been proposed: BayleyPinneau [1], Roche-Wainer-Thissen [2], Tanner-Whitehouse [3], etc., they are not really applicable for short children. Karlberg et al. analyzed a large number of longitudinal growth records as well as mid-parental height data and proposed probability charts for predicted final height [4].

In this study, by using a large number of longitudinal growth records, we have analysed the natural growth of children, including short and tall children during puberty and proposed probability estimates of final height.

Correspondence to: Dr. Toshiaki TANAKA, Director, Department of Endocrinology \& Metabolism, National Children's Medical Research Center, 3-35-31 Taishido, Setagaya-ku, Tokyo 154-8509, Japan

\section{Subjects and Methods}

Longitudinal growth data were collected from healthy subjects born between April 1975 and March, 1976 in Akita Prefecture. The study made use of 13,707 longitudinal records of individuals (6,749 boys and 6,958 girls). These subjects had undergone annual examinations from age 6 to age 17 years.

In a personal computer, individual annual data were plotted and fitted by means of a smoothing cubic spline function. An individual velocity curve was drawn and parameters characterizing the growth process, such as peak height velocity (PHV) and age at onset of pubertal growth spurt (PGS), were calculated directly from the estimated curves. The age at which the height velocity was lowest before the PGS was judged to be the onset of the PGS. The height at 17 years was defined as the final height. Pubertal height gain was defined as the height difference between height at onset of PGS and final height. 
A cross-sectional survey of national data conducted in Japan in 1992 was used as a growth reference to calculate standard deviation scores (SDS) [5].

\section{Results}

The children were divided into subgroups with 0.2 SD intervals according to height SDS at 6 years. Figure 1 shows final height SDS distribution as a percentile of subgroups against height SDS at 6 years in boys and girls. The median line of final height SDS demonstrates the tendency for shorter children at 6 years to increase their final height SDS and of taller children at 6 years to decrease their final height SDS. Girls showed the same tendency.

Median pubertal height gain, height at onset of PGS, height at PHV, and final height of subgroups are plotted against height SDS at 6 years as shown in Fig. 2. Since pubertal height gain is not significantly different among subgroups, final height depends on height at onset of PGS. Dotted lines in Fig. 2 demonstrate hypothetical height at PGS and final height if age at onset of PGS is the same as the mean age at onset of PGS in all subgroups. Since shorter children enter pubertal growth spurt later and taller children enter earlier than the mean age at PGS as shown Fig. 3, shorter children enter pubertal growth spurt at a taller height than the hypothetical height and taller children enter pubertal growth spurt at a shorter height than the hypothetical height. Therefore, short children at 6 years have a tendency to increase their final height SDS and tall children to decrease their final height SDS because pubertal height gain is almost the same in all subgroups at 6 years.

The percentage of final height distribution is calculated in subgroups of height SDS at 6 years and illustrated in Fig. 4. Since shorter children at 6 years have a tendency to increase final height by entering puberty later, only $30 \%$ of children at -2 SDS at 6 years remain below -2 SD as adults.

\section{Discussion}

It is well known that prepubertal height is an important predictor of final height, but final height is modified by puberty. The effect on changing height SDS was analyzed in a large population of children. Since median pubertal height gain is the same in all subgroups, final height depends on the height at onset of PGS. Shorter children at 6 years tend to increase their final height SDS by entering puberty later and making their height at onset of PGS relatively taller. On the other hand taller

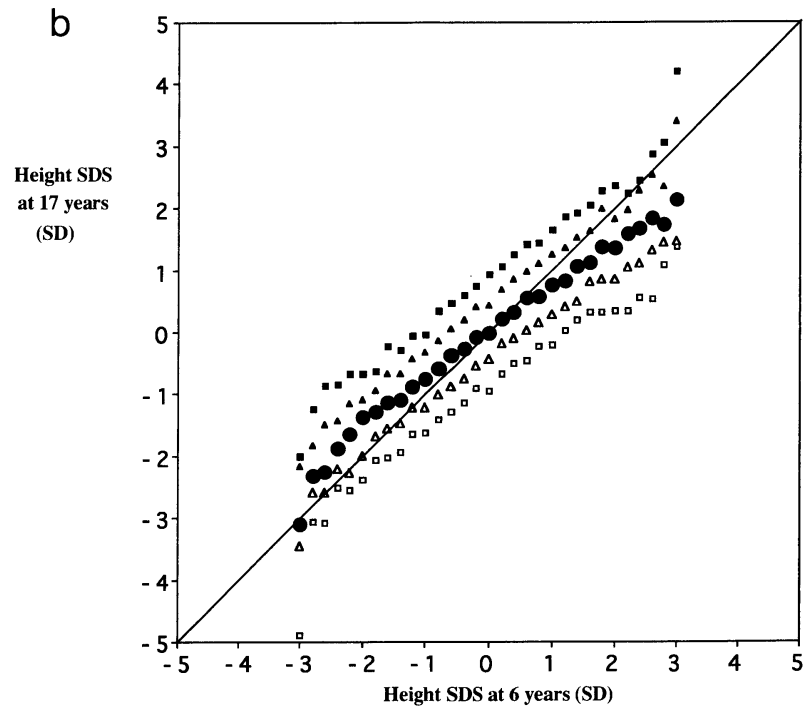

Fig. 1. Distribution of final height SDS against subgroups at 6 years. (a) boys, (b) girls. $\mathbf{\square}, 10$ th percentile; $\triangle, 25$ th percentile;, 50 th percentile; $\boldsymbol{\Delta}, 75$ th percentile; $\mathbf{U}, 95$ th percentile. 
a

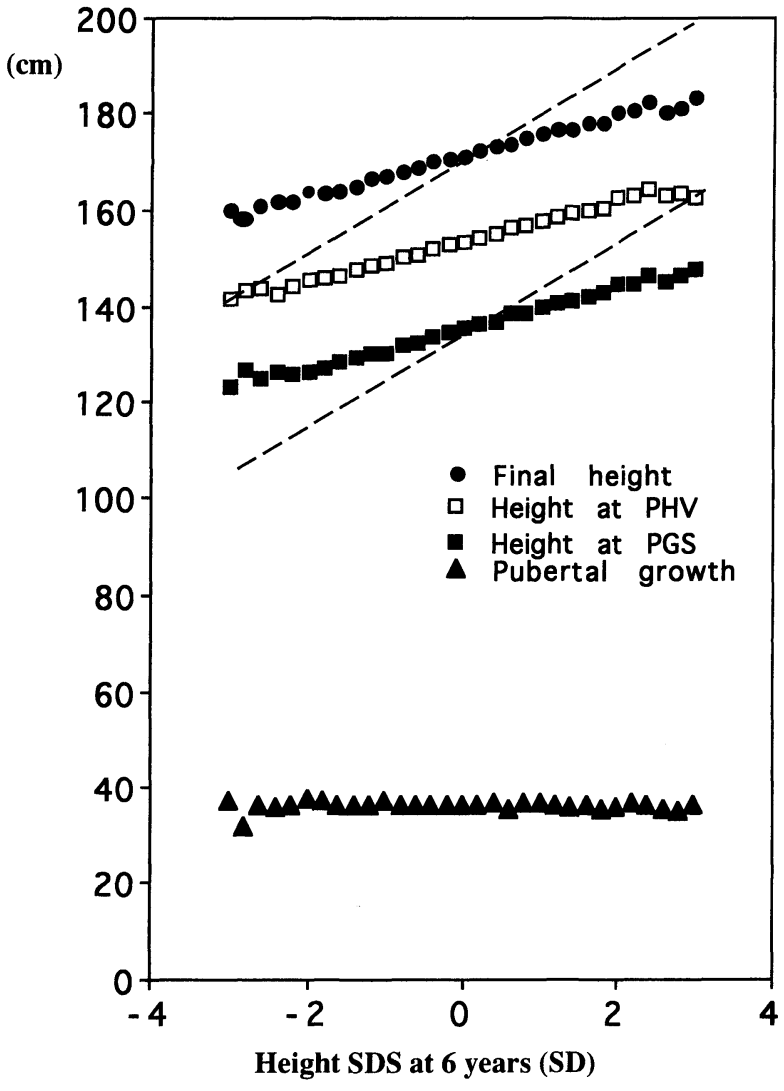

$\mathrm{b}$

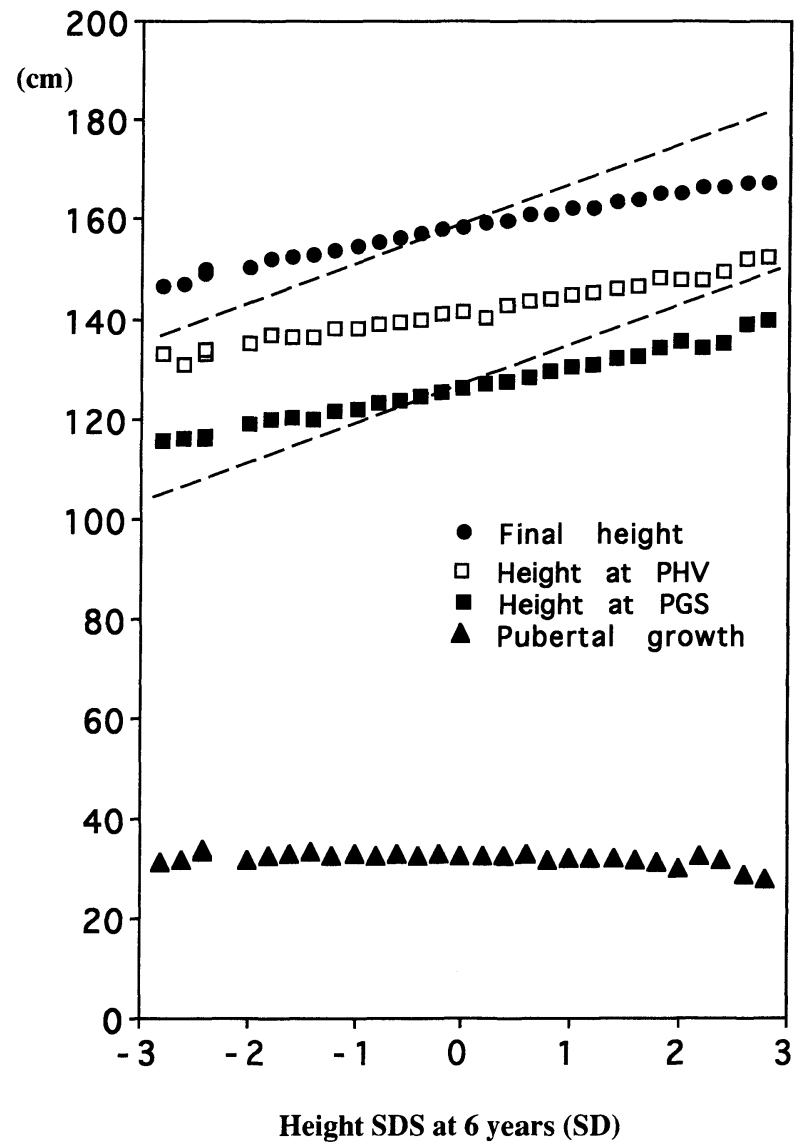

Fig. 2. Median pubertal growth, height at onset of PGS, height at PHV and final height of subgroups at 6 years. Dotted lines show the hypothetical height at PGS and final height if age at onset of PGS is the same as the mean age at onset of PGS in all subgroups. (a) boys, (b) girls.

children at 6 years tend to decrease their final height SDS by entering puberty early and make height at PGS relatively shorter. The percentage distribution of a final height SDS against subgroups at 6 years also shows this tendency. This figure is useful in predicting the probability of final height SDS in the clinical field of growth disorders.

\section{References}

1. Bayley N, Pinneau S (1952) Tables for predicting adult height from skeletal age. J Pediatr 40: 423441.

2. Roche AF, Wainer H, Thissen D (1975) The RWT method for the prediction of adult stature. Pediatrics 56: 1026-1033.

3. Tanner JM, Whitehouse RH, Marshall WA, Carter BS (1975) Prediction of adult height from height, bone age, and occurrence of menarche, at ages 4 to
16 with allowance for midparent height. Arch Dis Child 50: 14-26.

4. Karlberg J, Lawrence C, Albertsson-Wikland K (1994) Prediction of final height in short, normal, and tall children. Acta Paediatr 406 (suppl): 3-9.

5. Suwa S, Tachibana K (1993) Standard growth charts for height and weight of Japanese children from birth to 17 years based on a cross-sectional survey of national data. Clin Pediatr Endocrinol 2: 87-97. 
a

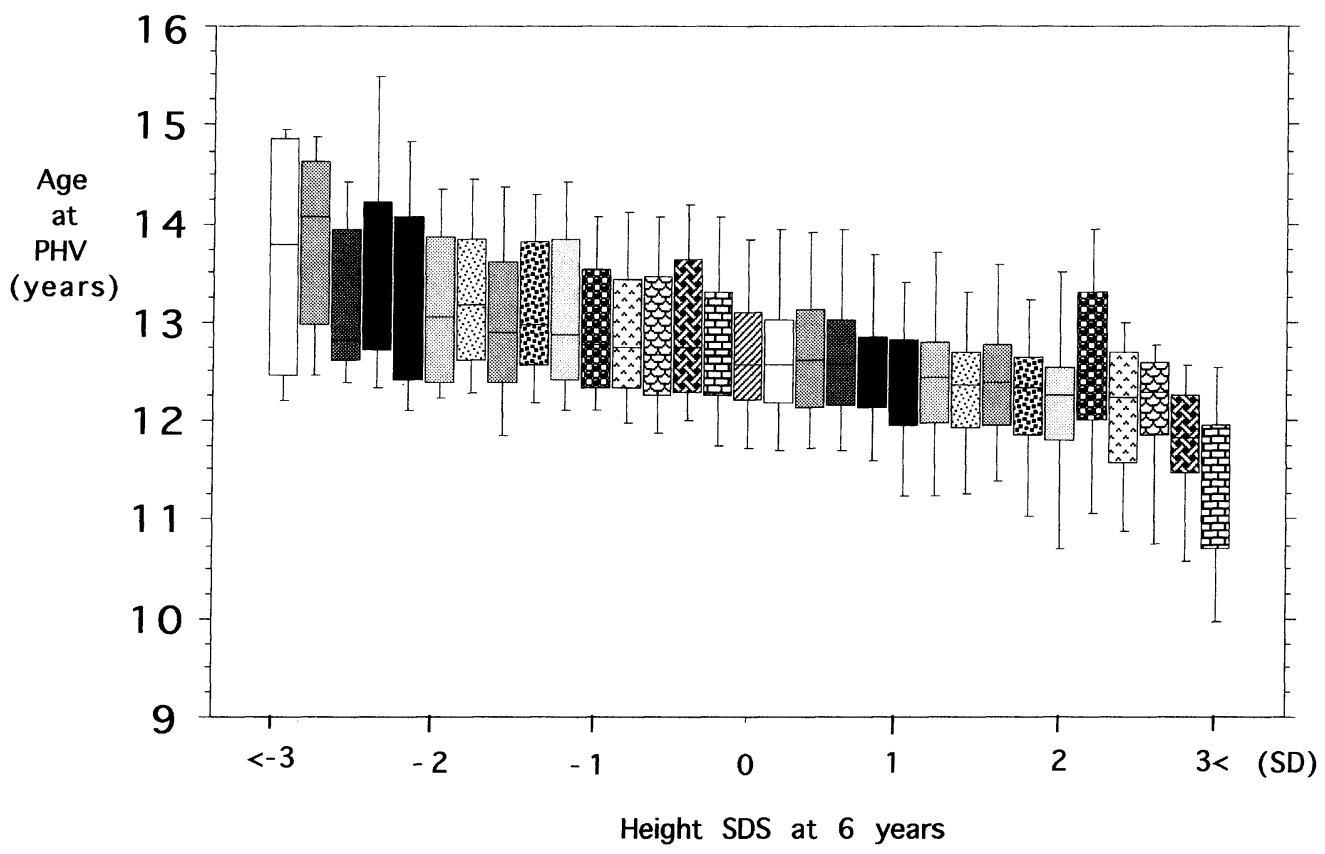

b

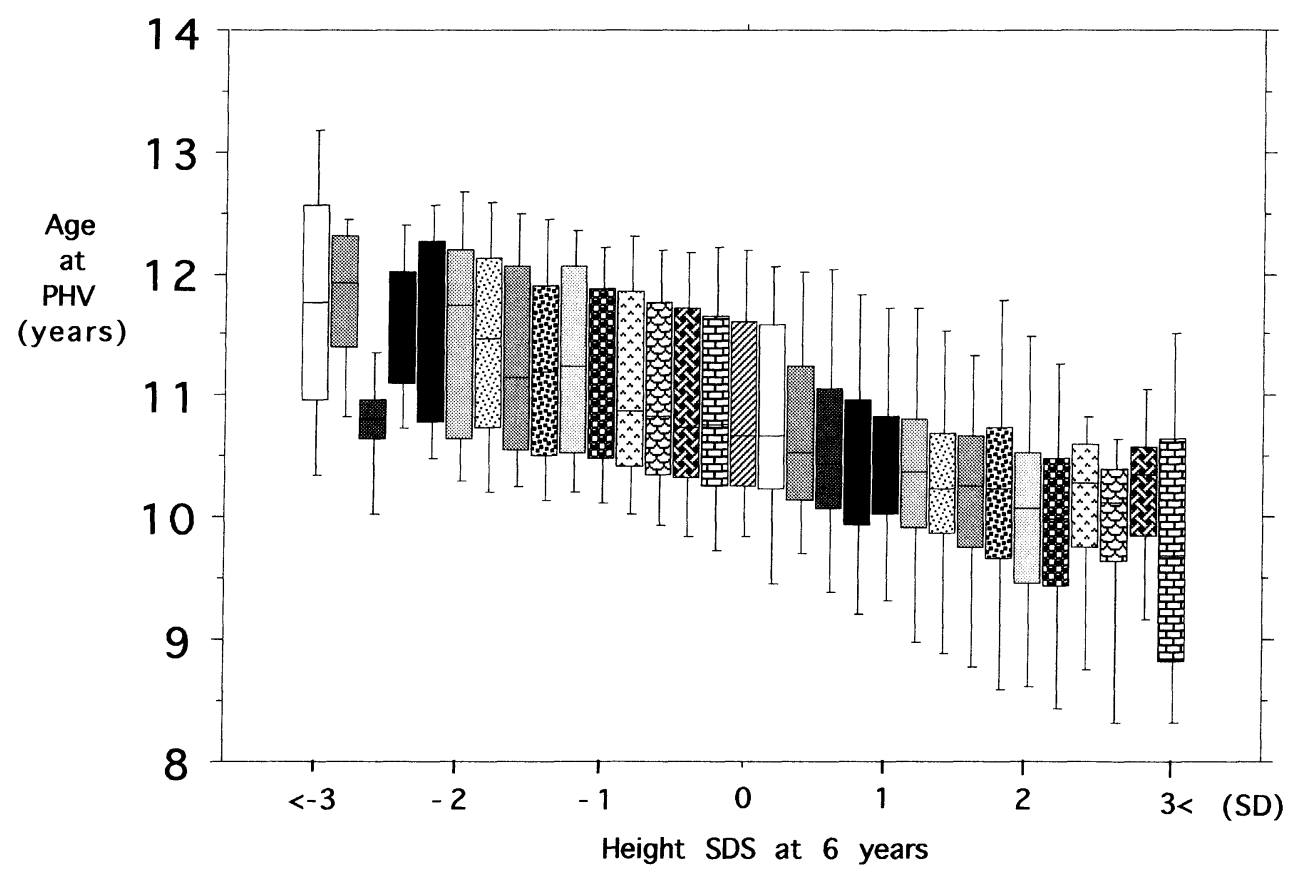

Fig. 3. Age at onset of PGS in subgroups at 6 years. (a) boys, (b) girls. 


\section{a}

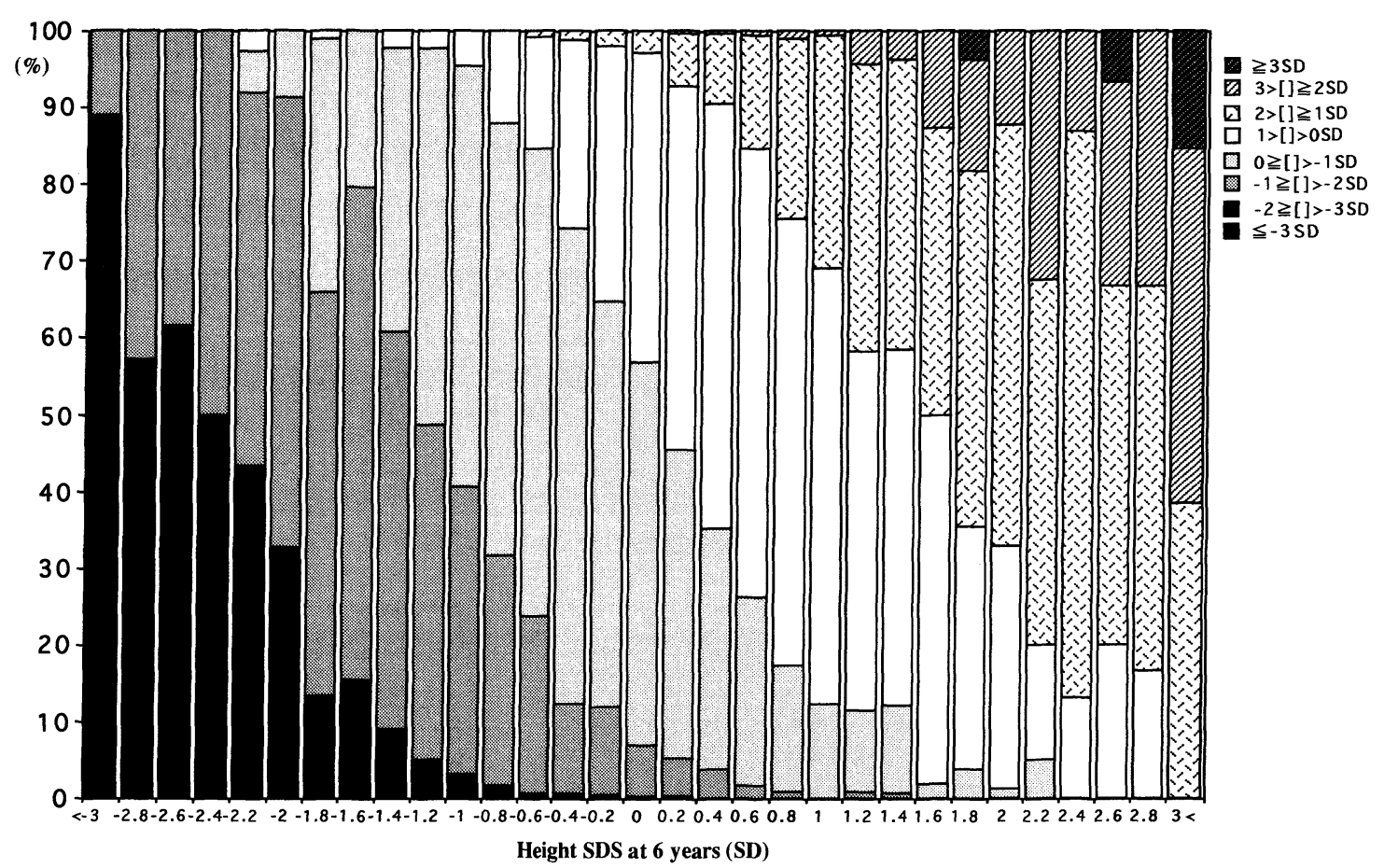

$\mathrm{b}$

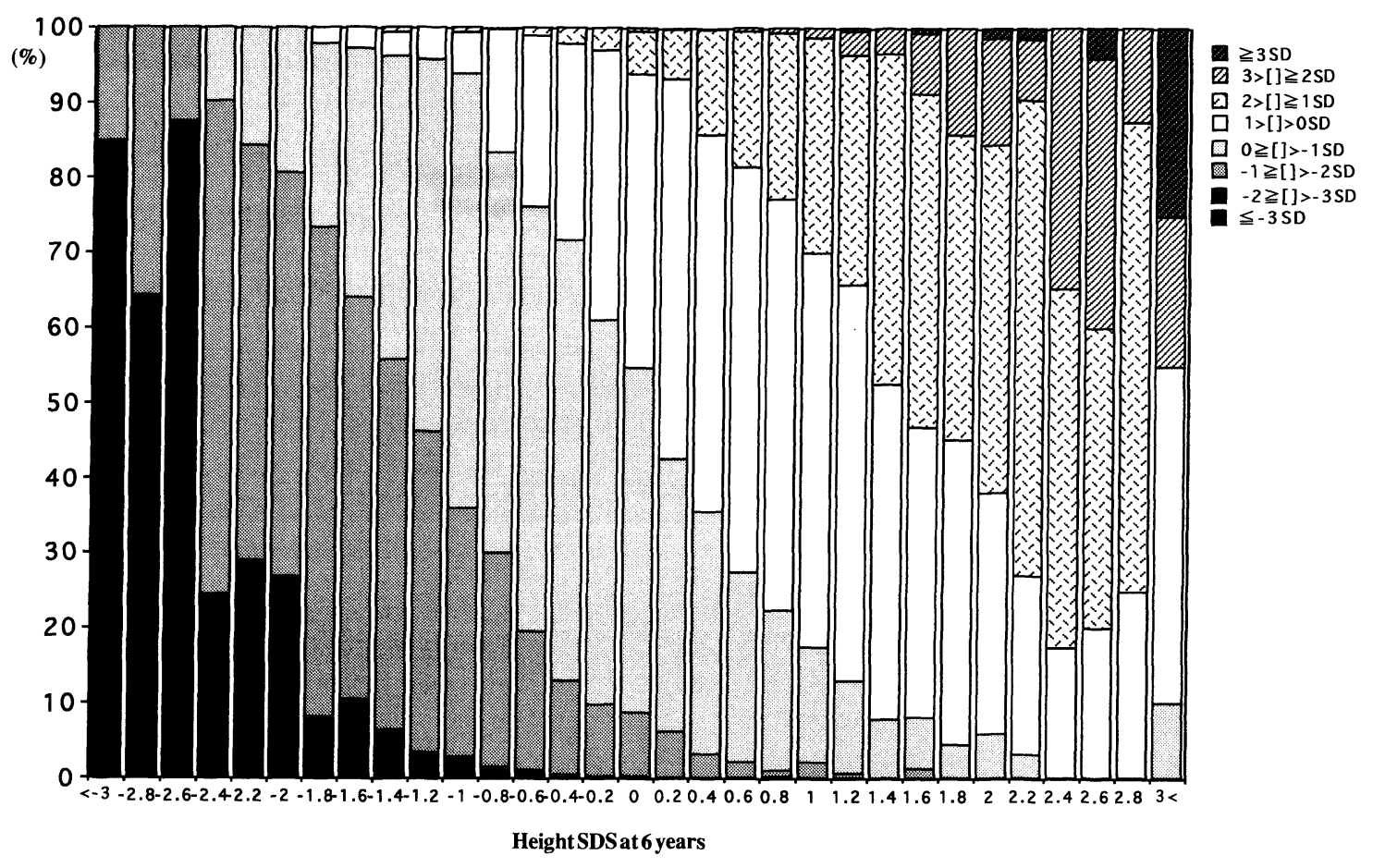

Fig. 4. Distribution of final height SDS in percentages against subgroups at 6 years. (a) boys, (b) girls. 